Gıdaları taklit eden solüsyonların bulk-fill kompozitlerin renklenmesine etkisi

\section{Effect of food simulating liquids on color stability of bulk-fill composites}

\author{
Uzm. Dt. Özge Gizem Cabadağ \\ Özel klinik, İstanbul \\ Orcid ID: 0000-00017898-9259
}

\section{Doç. Dr. Nihan Gönülol}

Ondokuz Mayıs Üniversitesi, Diş Hekimliği Fakültesi, Restoratif Diş Tedavisi A.D., Samsun

Orcid ID: 0000-0002-7046-7154

\section{Araş. Gör. Lena Almasifar \\ Ondokuz Mayıs Üniversitesi, Diş Hekimliği Fakültesi, Restoratif Diş Tedavisi A.D., Samsun \\ Orcid ID: 0000-0003-3493-0137}

\section{Dr. Öğr. Üyesi Tuğba Misilli}

Çanakkale Onsekiz Mart Üniversitesi,

Diş Hekimliği Fakültesi Restoratif Diş Tedavisi A.D., Çanakkale

Orcid ID: 0000-0003-0019-4872

Geliş tarihi: 16 Ocak 2020

Kabul tarihi: 27 Şubat 2020

doi: 10.5505/yeditepe.2020.35693

\section{Yazışma adresi:}

Dr. Öğr. Üyesi Tuğba Misilli

Çanakkale Onsekiz Mart Üniversitesi,

Diş Hekimliği Fakültesi,

Restoratif Diş Tedavisi Anabilim Dal,,

Merkez/Çanakkale

Tel: +905059392100

E-posta:dt.tugbay@outlook.com

\section{ÖZET}

Amaç: Bu çalışmanın amacı gıdaları taklit eden solüsyonlarda bekletilen yüksek viskoziteli bulk-fill kompozitlerin ve bir adet geleneksel kompozit rezinin renkledirici bir solüsyona maruz bırakılması sonrası renk değişimini değerlendirmektir.

Gereç ve Yöntem: 4 farklı yüksek viskoziteli bulk-fill kompozit (Tetric EvoCeram Bulk Fill, SonicFill, Filtek Bulk Fill Posterior, Beautifil Bulk Restorative) ve bir adet geleneksel mikrohibrit tipte kompozit rezin (Filtek Z250) kullanılarak, $8 \mathrm{~mm}$ çapında ve $4 \mathrm{~mm}$ kalınlığında disk şeklinde toplam 180 adet örnek hazırlandı. Hazırlanan örnekler gıdaları taklit eden solüsyonlarda (etanol, heptan, sitrik asit, yapay tükürük) bekletilmek üzere rastgele 4 alt gruba ayrıldı $(n=9)$ ve bu solüsyonlarda 7 gün süreyle $37 \pm 1^{\circ} \mathrm{C}^{\prime}$ de etüvde bekletildi. Ardından örneklerin tümü çözünebilir kahve solüsyonunda 6 gün süreyle tutuldu. Tüm örneklerden, gıdaları taklit eden solüsyonlarda bekletilmesi sonrası ve kahve solüsyonunda bekletilmesi sonrası Vita Easy-Shade (VITA Zahnfabrik) dijital spektrofotometre cihazı yardımıyla renk değerleri elde edildi. Renk değişim değerleri $(\triangle E 00), C I E D E 2000$ renk sistemine göre kaydedilerek, istatistiksel analizi için çift yönlü varyans analizi, ikili karşılaştırmalar için Bonferroni testi kullanıldı $(\alpha=.05)$.

Bulgular: Test edilen kompozit grupları arasında en yüksek $\Delta$ E00 değerleri Beautifil Bulk Restorative grubunda tespit edilirken ( $p<0.001)$, en fazla renk değişimi kahve solüsyonu öncesi sitrik asite maruz bırakıldığında gözlenmiştir ( $p=0.027$ ).

Sonuç: Gıdaları taklit eden solüsyonların ve materyallerin farklı yapısal özellikleri kompozit rezinlerin renk stabilitesinde etkilidir.

Anahtar kelimeler: bulk-Fill kompozitler, gıdaları taklit eden solüsyonlar, renklenme

SUMMARY

Aim: To evaluate the color stability of high-viscosity bulk-fill composites and a conventional composite stored in food-simulating liquids after subjected to staining solution.

Materials and Method: A total of 180 disc-shaped samples (8 $\mathrm{mm}$ diameter and $4 \mathrm{~mm}$ height) were prepared using 4 different high viscosity bulk-fill composites (Tetric EvoCeram Bulk Fill, SonicFill, Filtek Bulk Fill Posterior, Beautifil Bulk Restorative) and one conventional microhybrid type composite resin (Filtek Z250). The samples were randomly divided into 4 subgroups $(n=9)$ to be stored in food-simulating liquids (ethanol, heptane, citric acid, and artificial saliva) in an oven at $37 \pm 1^{\circ} \mathrm{C}$ for 7 days. Then, all samples were immersed in a soluble coffee solution for 6 days. The color measurements of all samples were performed after storage in food-simulating liquids and after storage in coffee solution with a digital spectrophotometer (Vita Easy-Shade, VITA Zahnfabrik). Differences in color measurements ( $\triangle \mathrm{E} 00$ ) were calculated according to CIEDE2000 formula. Data were statistically analyzed with two-way ANOVA and Bonferroni tests ( $\alpha=.05)$.

Results: Among the tested resin composite groups, the highest $\Delta \mathrm{E} 00$ values were detected in Beautifil Bulk Restorative 
$(p<0.001)$. Also, the highest color change in this composite group was observed when subjected to citric acid solution before the coffee solution $(p=0.027)$.

Conclusion: The different structural properties of food simulating liquids and materials affects the color stability of resin-based composites.

Key words: Bulk-fill composites, food-simulating liquids, discoloration.

\section{GíRiş}

Son yıllarda, rezin esaslı materyallerin özelliklerindeki gelişmelerin, artan estetik isteklere yanıt vermesi kullanım alanlarını daha da genişletmiştir. Ancak ağız ortamındaki pek çok durum kompozit restorasyonların bütünlüklerinde ve klinik ömürlerinde olumsuz etkiler oluşturabilmektedir.' Bireyin beslenme alışkanlıklarına bağlı olarak maruz kalınan besin içerikleri, materyallerin kimyasal yıkımına neden olarak kompozit restorasyonların yüzeyinde bir takım değişiklikler meydana getirmektedir. ${ }^{2}$ Bu değişiklikler, materyalin mekanik abrazyona karşı daha savunmasız, daha pürüzlü, renklenmelere ve plak birikimine daha elverişli bir yüzey yapısıyla, ilerleyen dönemlerde yumuşak doku inflamasyonuna ve rekürrent çürük oluşumuna kadar varabilen durumlar oluşturması nedeniyle büyük önem teşkil eder.3.4 Amerikan Gıda ve illaç Dairesi (FDA) rehberine göre gıdaları taklit eden solüsyonlar; sitrik asit, etanol, heptan olarak belirlenmiştir. Sitrik asit, içecekler, sebzeler, meyveler, şeker benzeri gıdalarda; etanol ise alkollü içecekler ve ağız gargaralarında bulunurken; heptan bitkisel ve hayvansal yağları simule etmektedir. ${ }^{5}$

Mükemmel estetiği sağlamak için, dental restoratif materyallerin yüzey renklenmesine dirençli olmaları yanında içsel renk stabilitesini de korumaları gerekir. ${ }^{6}$ Bu nedenle kompozit rezin renklenmelerinde yüzey özellikleri yanı sıra, rezinin ekstrinsik renklendirici maddelere olan afinitesi, polimerizasyon dönüşüm derecesi ve su emilim özellikleri de önemlidir.? Kompozit rezinlerin renklendirici içeren sıvıları absorbe etmesi renklenmeyle sonuçlanır. ${ }^{6}$ Kahve, çay, kırmızı şarap, meyve suyu, kola gibi yaygın olarak tüketilen içeceklerle yapılan çok sayıda in vitro çaıışmanın sonuçları da, restorasyon yüzeylerinde önemli ölçüde renk değişikliği meydana geldiğini göstermiştir. ${ }^{8,9}$ Bunların arasında kahve renklenmeye en çok sebep olan ve toplumumuzda oldukça sık tüketilen içeceklerden biridir. $^{10-12}$

Restoratif materyallerdeki renk değişimlerinin değerlendirilmesinde CIELab veya güncel olarak CIEDE2000 formüllerinden yararlanılmaktadır. CIEDE2000 ( $\triangle E$ E00) renk değişim formülü, Uluslararası Aydınlatma Komisyonu (CIE, Commission Internationale de l'Eclairage) tarafından tüm değişkenlerin eşit değerlendirildiği CIELab $(\Delta \mathrm{E} * \mathrm{ab})$ sistemindeki eksiklikleri gidermek için gözün algısını daha baskın biçimde etkileyen faktörlerde modifikasyonlara gidilerek, kabul edilebilir ve algılanabilir renk değişimini daha uygun ve doğru biçimde saptayabilmek amacıyla geliştirilmiş bir formüldür. ${ }^{13}$

Bu çalışmada, klinik kullanımları gün geçtikçe yaygınlaşan bulk-fill kompozitlerin, gıdaları taklit eden solüsyonlara maruz kalması sonrasında yüzeylerinde oluşan değişimlere bağlı olarak, kahve solüsyonunda bekletilmesi ile meydana gelen renk değişimlerinin geleneksel bir rezin kompozit ile CIEDE2000 renk formülasyonu kullanılarak karşılaştırmalı olarak incelenmesi amaçlanmıştır.

Çalışmanın sıfır hipotezi, gıdaları taklit eden solüsyonların test edilen bulk-fill ve geleneksel kompozit grupları üzerinde kahvede bekletme sonrası renk değişimleri açısından herhangi bir fark yaratmayacağıdır.

\section{GEREÇ ve YÖNTEM}

Bu çalışmada 4 farklı yüksek viskoziteli bulk-fill kompozit (Tetric EvoCeram Bulk Fill, SonicFill, Filtek Bulk Fill Posterior Restorative, Beautifil-Bulk Restorative) ve bir adet geleneksel mikrohibrit tipte kompozit rezin (Filtek Z250) ve gıdaları taklit eden 3 farklı solüsyon [Etanol (Teksoll 96\%, Tekkim Kimya Sanayi Tic. Ltd. Sti.), heptan (n-Heptan, Tekkim Kimya Sanayi Tic. Ltd. Sti.), sitrik asit (Sitrik asit \%10, Norateks)] ve kontrol grubu olarak yapay tükürük kullanılmıştır.

Çalışmada kullanılan kompozit rezinlerin içerikleri, özellikleri ve üretici firma bilgileri Tablo 1'de, gıdaları taklit eden solüsyonların içerikleri ise Tablo 2 'de verilmiştir.

\begin{tabular}{|c|c|c|c|c|c|}
\hline Grup & Materyal & Rezin matriks & Doldurucu tipi & $\begin{array}{l}\text { Doldurucu oram \%v, } \\
\text { boyutu }\end{array}$ & $\begin{array}{l}\text { Üretici Firma } \\
\text { Seri No. }\end{array}$ \\
\hline Z250 & Filtek Z250 & $\begin{array}{l}\text { Bis-GMA, Bis- } \\
\text { EMA, UDMA, } \\
\text { TEGDMA }\end{array}$ & Zirkonyum/silika & $\begin{array}{c}\% 60 \\
0.01-3.5 \mu \mathrm{m} \\
\text { (ort:0.6 } \mu \mathrm{m} \text { ) }\end{array}$ & $\begin{array}{l}\text { 3M ESPE, St } \\
\text { Paul, MN, ABD } \\
\text { N905168 }\end{array}$ \\
\hline TEC & $\begin{array}{c}\text { Tetric } \\
\text { EvoCeram } \\
\text { Bulk Fill }\end{array}$ & $\begin{array}{l}\text { BisGMA, } \\
\text { UDMA, Bis- } \\
\text { EMA }\end{array}$ & $\begin{array}{l}\text { Ba-Al-Si-cam, } \\
\text { prepolimer } \\
\text { doldurucu, sferik } \\
\text { karıșik oksit, } \\
\mathrm{YbF}_{3} \\
\end{array}$ & $\begin{array}{c}\% 60-61 \\
0.04-3 \mu \mathrm{m} \\
\text { (ort: } 0.55 \mu \mathrm{m} \text { ) }\end{array}$ & $\begin{array}{l}\text { Ivoclar Vivadent, } \\
\text { Schaan, } \\
\text { Liechtenstein } \\
\text { U26276 }\end{array}$ \\
\hline BBR & $\begin{array}{l}\text { Beautifil-Bulk } \\
\text { Restorative }\end{array}$ & $\begin{array}{l}\text { Bis-GMA, } \\
\text { UDMA, } \\
\text { Bis-MPEPP, } \\
\text { TEGDMA } \\
\end{array}$ & $\begin{array}{l}\text { Floro-alumino- } \\
\text { silikat cam bazlı } \\
\text { S-PRG doldurucu }\end{array}$ & $\% 74.5$ & $\begin{array}{l}\text { SHOFU Inc., } \\
\text { Kyoto, Japonya } \\
051727\end{array}$ \\
\hline $\mathrm{FBF}$ & $\begin{array}{l}\text { Filtek Bulk } \\
\text { Fill Posterior } \\
\text { Restorative }\end{array}$ & $\begin{array}{l}\text { AUDMA, } \\
\text { UDMA, } \\
\text { (1,12-dodecane- } \\
\text { DMA) }\end{array}$ & $\begin{array}{l}\text { Silika, zirkonyum, } \\
\text { ytterbium } \\
\text { trifluoride }\end{array}$ & $\begin{array}{c}\% 58.4 \\
(20 \mathrm{~nm} \text { silika, } 4-11 \mathrm{~nm} \\
\text { zirkon, } 100 \mathrm{~nm} \text { YbF }\end{array}$ & $\begin{array}{c}\text { 3M ESPE, St } \\
\text { Paul, MN, ABD } \\
\text { N880335 }\end{array}$ \\
\hline SF & SonicFill & $\begin{array}{l}\text { Bis-GMA, Bis- } \\
\text { EMA, TEGDMA, } \\
\text { EBPDMA }\end{array}$ & $\mathrm{SiO}_{2}$, cam, oksit & $\begin{array}{c}\% 66 \\
(25-400 \mathrm{~nm})\end{array}$ & $\begin{array}{c}\text { Kerr, Orange, CA, } \\
\text { ABD } \\
6385712\end{array}$ \\
\hline
\end{tabular}

Tablo 2. Çalışmada kullanılan gıdaları taklit eden solüsyonlar

\begin{tabular}{cl}
\hline Bekletme Ortamı & \\
\hline & $125.6 \mathrm{mgL}^{-1} \mathrm{NaCl}_{1}, 963.9 \mathrm{mgL}^{-1} \mathrm{KCl}, 189.2$ \\
& $\mathrm{mgL}^{-1} \mathrm{KSCN}, 654.5 \mathrm{mgL}^{-1} \mathrm{KH}_{2} \mathrm{PO}_{4}, 200.0$ \\
Yapay tükürük & $\mathrm{mgL}^{-1} \mathrm{Urea}_{2} 763.2 \mathrm{mgL}^{-1} \mathrm{NaSO}_{4} .10 \mathrm{H}_{2} \mathrm{O}$, \\
& $178.0 \mathrm{mgL}^{-1} \mathrm{NH}_{4} \mathrm{Cl}, 227.8 \mathrm{mgL}^{-1}$ \\
& $\mathrm{CaCl}_{2} .2 \mathrm{H}_{2} \mathrm{O}, 630.8 \mathrm{mgL}^{-1} \mathrm{NaHCO}_{3}$ \\
\hline & Simulasyon Tipi \\
\hline Heptan & Tereyağı, bitkisel ve hayvansal yağlar \\
Sitrik asit (\%10) & İecekler, sebzeler, meyveler, şeker, şurup \\
Etanol (\%96) & Alkollü içecekler, ağız gargaraları \\
\hline
\end{tabular}

Çalışmada kullanılan toplam 180 adet disk şeklindeki kompozit örnekler ( $N=180)$, her bir kompozit grubu için 36 'şar adet örnek olmak üzere $8 \mathrm{~mm}$ çapında ve $4 \mathrm{~mm}$ kalınlığında paslanmaz çelik kalıplarda, bulk-fill kompozit rezinler tek tabaka halinde, geleneksel kompozit rezin üretici firma talimatlarına uygun olarak $2 \mathrm{~mm}$ 'lik tabakalar halinde yerleştirilerek ve LED ışık kaynağı [Elipar S10 (3M ESPE, St. Paul, MN, ABD)] ile 20 s süreyle polimerize 
edilerek hazırlandı. Her beş örnekte bir polimerizasyondan önce ışık kaynağının gücü kontrol edilip, 1000 mW/ $\mathrm{cm}^{2}$ den yüksek olduğuna emin olundu. Işık uygulamasının hemen ardından kompozit rezin örneklerin ışık uygulanan yüzeyleri alüminyum oksit (Al2O3) emdirilmiş diskler (Sof-Lex XT, 3M ESPE, St Paul, MN, ABD) ile cilalandı. Her bir kompozit grubundaki örnekler numaralandırılıktan sonra gıdaları taklit eden solüsyonlarda bekletilmek üzere 4 alt gruba $(n=9)$ ayrıldı ve farklı saklama solüsyonlarının bulunduğu tüplere konarak 7 gün süreyle $37 \pm 1^{\circ} \mathrm{C}^{\prime}$ de etüvde bekletildi. Gıdaları taklit eden solüsyonlar, esasında renklendirme özellikleri baskın olmayan ancak kompozit materyallerin yüzeyinde ve yapısında farklııklar yaratabilen solüsyonlardır. Bu nedenle bu solüsyonlara maruziyet sonrası kompozit rezinlerde meydana gelebilecek bozunmanın, materyallerin renk değişimine etkisinin ölçülmesi amaçlanarak, başlangıç renk ölçümleri örnekler 7 gün solüsyonda bekletildikten sonra yapıldı. Başlangıç renk değerleri, dental spektrofotometre (Vita Easyshade, Bad Sackingen, Almanya) kullanılarak, standart beyaz bir zemin üzerinde ölçümün üç kez tekrarlanmasının ardından, ortalama L, a, b değerleri olarak kaydedildi. Ölçümler D65 standart aydınlatma koşullarında yapıldı ve her ölçümden önce cihaz, üretici firma önerileri doğrultusunda kalibre edildi. Bu işlemin ardından $3.6 \mathrm{~g}$ kahve (Nescafe Classic, Nestle, İsviçre) $300 \mathrm{ml}$ kaynamış distile suya ilave edilip 10 dakika karıştırıldıktan sonra filtre kağıdı ile filtre edildi. Başlangıç renk ölçümleri yapılan örnekler küvetlere yerleştirildikten sonra hazırlanan kahve solüsyonları ilave edildi ve etüv cihazında (EN025, Nüve, Türkiye) $37^{\circ} \mathrm{C}^{\prime}$ de 6 gün boyunca bekletildi. Bu sürenin sonunda etüvden çıkarılan örnekler distile suda yıkanarak kurutma kağıdı ile kurulandı. Örneklerden daha önce tarif edildiği şekilde 2. renk ölçüm değerleri elde edildi. Materyallerde meydana gelen renk değişim düzeyleri CIEDE2000 formülasyonu kullanılarak, hesaplandı:

$$
\Delta E_{00}=\left[\left(\frac{\Delta L^{\prime}}{K_{\mathrm{L}} S_{\mathrm{L}}}\right)^{2}+\left(\frac{\Delta C^{\prime}}{K_{\mathrm{C}} S_{\mathrm{C}}}\right)^{2}+\left(\frac{\Delta H^{\prime}}{K_{\mathrm{H}} S_{\mathrm{H}}}\right)^{2}+\mathrm{R}_{\mathrm{T}}\left(\frac{\Delta C^{\prime}}{K_{\mathrm{C}} S_{\mathrm{C}}}\right)\left(\frac{\Delta H^{\prime}}{K_{\mathrm{H}} S_{\mathrm{H}}}\right)\right]^{\frac{1}{2}}
$$

İstatistiksel analizler SPSS 20.0 (SPSS Inc. Chicago, IL, ABD) programı kullanılarak gerçekleştirildi. Verilerin normal dağılıma uygunluğunun Shapiro-Wilk testi ile kontrolü ardından iki yönlü varyans analizi ve ikili karşılaştırmalar için Bonferroni testi kullanılarak istatistiksel analiz tamamlandı. İstatistiksel olarak anlamlılık düzeyi $\mathrm{p}<0.05$ olarak kabul edildi.

\section{BULGULAR}

Farklı sıvilarda bekletilmiş 5 farklı kompozit grubunun kahve solüsyonuna maruz bırakııması sonrası elde edilen renk değişim değerlerinin ( $\triangle \mathrm{E} 00$ ) ortalamaları ve standart sapmaları Tablo 3'te gösterilmiştir.
Tablo 3. Renk değişikliği sonrası ortalama $\triangle \mathrm{E} 00 \pm$ standart sapmaları değerler

\begin{tabular}{ccccccc}
\hline & Z250 & FBF & BBR & TEC & SF & p değeri \\
\hline Tükürük & $3.95 \pm 0.46^{\mathrm{a}}$ & $2.58 \pm 0.23^{\mathrm{b}}$ & $4.02 \pm 1.87^{\mathrm{B}, \mathrm{a}}$ & $2.05 \pm 0.25^{\mathrm{b}}$ & $2.93 \pm 0.65^{\mathrm{AB}, \mathrm{al}}$ & $<0.001$ \\
\hline Sitrik asit & $3.57 \pm 0.54^{\mathrm{b}}$ & $1.95 \pm 0.27^{\mathrm{c}}$ & $5.44 \pm 1.2^{\mathrm{A}, \mathrm{a}}$ & $1.9 \pm 0.67^{\mathrm{c}}$ & $3.59 \pm 0.19^{\mathrm{A}, \mathrm{b}}$ & $<0.001$ \\
\hline Heptan & $3.23 \pm 0.58^{\mathrm{b}}$ & $1.79 \pm 0.24^{\mathrm{c}}$ & $4.67 \pm 2,64^{\wedge \mathrm{AB}, \mathrm{a}}$ & $2.01 \pm 0.57^{\mathrm{bc}}$ & $1.82 \pm 0.29^{\mathrm{B}, \mathrm{c}}$ & $<0.001$ \\
\hline Etanol & $3.24 \pm 0.34^{\mathrm{b}}$ & $2.5 \pm 0.27^{\mathrm{b}}$ & $4.56 \pm 2.18^{\mathrm{AB}, \mathrm{a}}$ & $2.25 \pm 0.2^{\mathrm{b}}$ & $2.47 \pm 0.44^{\mathrm{AB}, \mathrm{b}}$ & $<0.001$ \\
\hline p değeri & 0.363 & 0.236 & 0.027 & 0.897 & 0.002 & \\
\hline
\end{tabular}

Farklı büyük harfler, aynı sütun içindeki istatistiksel olarak anlamlı farklııkları ifade etmektedir. Farklı küçük harfler, aynı satır içindeki istatistiksel olarak anlamlı farklılıkları ifade etmektedir

Yapılan iki yönlü varyans analizi, renk değişim değerleri üzerinde kompozit materyallerin $(<0.001)$, bekletme ortamlarının (0.043) ve bunların interaksiyonunun (0.022) önemli etkisi olduğunu göstermiştir.

Her bir bekletme ortamı için yapılan kompozit grupları arasındaki karşılaştırmalar, yapay tükürükte bekletilen Beautifil Bulk Restorative (BBR) $(4.02 \pm 1.87)$ ve Filtek Z250 (Z250) gruplarında (3.95 \pm 0.46$)$, Tetric EvoCeram Bulk Fill (TEC) $(2.05 \pm 0.25)$ ve Filtek Bulk Fill Posterior Restorative (FBF) $(2.58 \pm 0.23)$ gruplarına göre daha fazla renk değişimi meydana geldiğini göstermiştir $(<0.001)$. Bekletme ortamı sitrik asit olduğunda, en fazla renk değişimi BBR grubunda $(5.44 \pm 1.2)$ tespit edilmiş, bunu sırasıyla Z250, SonicFill (SF), FBF ve TEC grupları takip etmiştir. Diğer yandan Z250 - SF ve FBF - TEC grupları arasında istatistiksel olarak anlamlı bir farka rastlanmamıştır. Heptanda bekletilen örnekler arasında da benzer şekilde en fazla renk değişimi BBR grubunda (4.67 \pm 2.64$)$ meydana gelirken, takip eden Z250 grubu kahve solüsyonuna maruz bırakılması sonraSı SF $(1.82 \pm 0.29)$ ve FBF $(1.79 \pm 0.24)$ gruplarına göre daha fazla renk değişimi göstermiştir $(<0.001)$. Etanolde bekletilen örneklerde de kahve solüsyonuna maruz bırakma, en fazla renk değişimini BBR grubunda $(4.56 \pm 2.18)$ meydana getirmiş (<0.001), diğer kompozit grupları arasında istatistiksel olarak anlamlı farka rastlanmamışıı.

Her bir kompozit grubu farklı bekletme ortamları açısından değerlendirildiğinde ise sadece BBR $(p=0.027)$ ve SF ( $p=0.002)$ gruplarında istatistiksel olarak anlamlı fark bulunmuştur. Hem BBR hem de SF grubu için en fazla renklenme sitrik asitte gözlenirken (sırasıyla 5.44 \pm 1.2 ; $3.59 \pm 0.19$ ), en az renklenme BBR için tükürükte, SF için heptanda bekletme sonrası kahveye maruz kalan örneklerde tespit edilmiştir (sırasıyla 4.02 $\pm 1.87,1.82 \pm 0.29$ ).

\section{TARTIŞMA}

Gıdaları taklit eden solüsyonların test edilen bulk-fill ve geleneksel kompozit grupları üzerinde kahvede bekletme sonrası renk değişimleri açısından herhangi bir fark yaratmayacağı şeklinde belirlenen hipotezimiz, solüsyonların farklı derecelerde renk değişimine neden olması nedeniyle reddedilmiştir.

Ağız, intraoral şartların çeşitliliği ve karmaşıklığı sebebiyle, restorasyonların davranışlarını simule etmek için, taklit edilmesi zor bir test ortamıdır. Fakat ağız ortamının taklit edildiği in vitro modeller, biyolojik bozulmanın te- 
mel mekanizmasını anlamak için ipucu sağlamaları açısından önem taşırlar. ${ }^{14}$ Diş hekimliği pratiğinde kullanılan materyallerin ağız içerisinde uzun süre en etkin şekilde fonksiyon görmeleri beklenmektedir. Ancak restoratif materyaller ömürlerini ve kullanımlarını olumsuz yönde etkileyebilecek gıdalar, kimyasal ajanlar, kullanılan ilaçlar, $\mathrm{pH}$ değişimleri, sıcaklık değişimleri gibi pek çok faktörle temas halindedir. ${ }^{15} \mathrm{Bu}$ faktörlerin yaratmış oldukları etkilerin simule edildiği in vitro modeller, kompozitlerin FDA tarafından gıdaları taklit eden solüsyonlar olarak belirlenen, belli çözücüler içinde bekletilmesi yoluyla oluşturulabilir.16 Sitrik asit, heptan, etanol-su ve distile su bu solüsyonlar arasındadır. Literatür taraması yapıldığında gıdaları taklit eden solüsyonların, kompozit materyallerin çeşitli özellikleri üzerindeki etkilerinin değerlendirildiği pek çok çalışmaya rastlanmaktadır. Bu çalışmalarda kompozit materyallerin yüzey pürüzlüğü, yüzey mikrosertlik değerleri, ${ }^{17}$ viskoelastisite ${ }^{18}$ ve bükülme dayanımı ${ }^{19}$ gibi farklı özellikleri üzerindeki etkilerinin araştıııldığı görülmektedir.

Chaidwic ve ark. ${ }^{20}$ kompozit rezinlerin mekanik ve fiziksel özelliklerindeki değişimi, 1 hafta ve 1 yıl kadar suda bekleterek değerlendirdikleri bir çalışmada iki değerlendirme periyodu arasında anlamlı bir farka rastlamamışlardır. Diğer yandan Örtengren ve ark. ${ }^{21}$ da yapıdan uzaklaşan organik komponentlerin çoğunun ilk 7 günde yapıyı terk ettiğini belirtmişlerdir. Bu bilgiler doğrultusunda çalışmada ağız içi sıvılarda bekletme periyodunun 7 gün olması planlanmıştır.

Renklenme problemi halen kompozit rezinlerdeki başarısızlık sebeplerinin ilk sıralarında yer almaktadır. Renklenme nedeniyle meydana gelen uyumsuz görüntü ve estetik kaygılar, restorasyonların yenilenmesi seçeneğini düşündürmekte ve bu durum ise sağlam diş yapısında azalma, zaman ve iş gücü harcanması gibi olumsuzlukları beraberinde getirmektedir. Rezin kompozitlerdeki renk değişimi, pek çok in vitro çalışmada farklı renklendirici içeceklerle incelenmiş, ${ }^{22-24}$ çalışmaların bir kısmında kahvenin rezin kompozitler için en renklendirici içeceklerden biri olduğu rapor edilmiştir. ${ }^{25,26}$ Kahvenin, farklı polarite ve polimerlere güçlü bir afiniteye sahip olan sarı renklendirici pigmentinin, kompozit rezinlerde renk değişimine neden olabileceği bildirilmiştir. ${ }^{24,25}$ Ertaş ve ark..$^{22}$ ise farklı içeceklerde bekletme sonrası kompozitlerin renk stabilitelerini değerlendirdikleri çalışmalarında, 24 saatlik in vitro depolamanın, yaklaşık olarak in vivo yaşlanmada 1aya eşdeğer olduğunu rapor etmişlerdir. Bu çalışmada örnekleri kahvede 6 gün bekleterek, 6 aylık kahve tüketiminin taklit edilmesi amaçlanmıştır.

Standart parametreler kullanarak renk değişimini tespit edilebilir ve mevcut renkleri objektif olarak değerlendirilebilir seviyeye getiren renk biliminde, ilk aşama olan rengin sayısallaştırııması amacıyla kullanılan spektrofotometreler, en güvenilir renk ölçüm cihazlarındandır. ${ }^{27}$ Renk farklılıklarının hesaplanmasında ise CIELab ve güncel olarak CIEDE2000 en sık kullanılan sistemlerdir. Çalışmalar CIEDE2000 renk formülünün, dental materyallerdeki translüsensi ve renk değişiminin değerlendirilmesinde algılanabilirlik ve kabul edilebilirlik noktasında CIELab formülünden daha iyi bir uyum sağladığını göstermiştir. ${ }^{28,29}$ Algılanabilirlik, bir diş ve bitişik renklenmiş restorasyon arasındaki renk farkının tespitini belirtirken; kabul edilebilirlik, bu restorasyon için kabul edilebilir olan renk farkını tanımlar. ${ }^{30,31}$ ISO/TR 28642:2016 standartlarına göre renk değişimi için eşik değerleri Paravina ve ark. ${ }^{32}$ çalışmalarında tespit ettikleri şekilde, algılanabilirlik için 0.8; kabul edilebilirlik için 1.8 olarak kabul edilmektedir. Bu çalışmada renk değişimlerinin tespiti için güncel literatüre uygun olarak CIEDE2000 formülünden yararlanılmıştır.

Rezin kompozitlerin renklenmeye karşı gösterdikleri direnç; rezin matriks yapısı, su emilimi, doldurucu partikül büyüklüğü, yapısı, matriks-doldurucu bağlantısının devamlılığı ile yüzeye uygulanan bitirme ve cila işlemleri gibi parametrelerden etkilenmektedir. ${ }^{33}$ Doldurucu-matriks arayüzünde bulunan mikro çatlaklar ve mikro boşluklar, renklendirici maddeler için en muhtemel penetrasyon yollarıdır. Aşınma ve kimyasal bozulmanın neden olduğu yüzey pürüzlülüğü de parlaklığı etkileyerek dış renklenmeyi artırabilir. ${ }^{34}$ Bu çalışmada yapay tükürük de dahil olmak üzere gıdaları taklit eden solüsyonlarda bekletildikten sonra kahveye konulan kompozit materyalleri arasında en yüksek $\Delta \mathrm{E} 00$ değerleri, Beautifil Bulk Restorative grubunda tespit edilmiştir. Bu durumun çalışmada kullanılan diğer kompozit gruplarından farklı olan yapısı nedeniyle olduğu düşünülmektedir. Beautifil Bulk Restorative, 'SelfPre Reacted Glass (S-PRG)' doldurucu olarak adlandırılan inorganik yapıya sahip, flor salımı ve reşarj özelliği gösterebilen giomer yapılı bir restoratif materyaldir. Kooi ve ark. ${ }^{35}$ gıdaları taklit eden solüsyonların giomer restoratif materyaller ile direkt ve indirekt hibrit kompozitler üzerindeki etkilerini inceledikleri araştırmalarında, giomerlerin bu solüsyonlarca yıkıma uğradığı, yüzey sertliğinin sitrik asit ve etanolden belirgin şekilde etkilendiğini, sitrik asitin yüzey pürüzlülüğünde belirgin artışa sebep olduğunu rapor etmişlerdir. Bu durumun nedeninin ise fluorosilikat cam doldurucuların, zayıf asitlerin bozunmasına karşı daha fazla duyarlı olmasından kaynaklanabileceği bildirilmiştir. ${ }^{35,36} \mathrm{Bu}$ çalışmada da Beautifil Bulk Restorative grubundaki örneklerin renk değişimindeki en belirgin artışın sitrik asit solüsyonunda bekletildiği durumlarda olduğu gözlenmiştir. Yüzey pürüzlüğündeki artış nedeniyle renklenme miktarının da artacağı göz önünde bulundurulduğunda, bu sonuçlar önceki çalışmanın bulgularıyla uyumludur. Diğer yandan nanodoldurucu yapısındaki kompozit materyallerin (Tetric EvoCeram Bulk Fill, Filtek Bulk Fill ve Sonic Fill) kahvede bekletilmesi sonrası daha düşük renk değişimi göstermesi, küçük partikül yapısın- 
dan kaynaklı daha pürüzsüz yüzey yapısı nedeniyle dışsal renklenmelere daha az duyarlı oluşuyla açıklanabilir.

Kompozit rezinlerin uzun dönemli stabilitelerini değerlendiren birçok çalışmada, gıdaları taklit etmek için kullanılan etanolün kompozitlerin sertliğini azaltıcı, rezin matriksi plastize edici etkileri gösterilmiştir. ${ }^{37,38}$ Etanol, Bis-GMA esaslı rezinlere yakın çözünürlük indeksine sahip olmasının yanında, molekül ağırlığı sebebiyle sudan daha yüksek seviyede geçirgenlik göstermektedir. Organik bir sıvı olan etanol, kolay penetrasyon özelliği ile rezin matriksin bozularak yumuşamasına sebep olur. ${ }^{39}$ Gökay ve ark. ${ }^{40}$ çeşitli solüsyonların (distile su, \%25-50 etanol, sitrik asit, laktik asit, heptan) farklı kompozit rezinler üzerindeki etkilerini kıyasladıkları çalışmalarında, en düşük yüzey sertlik değerlerinin \%50 etanol solüsyonunda bekletilen kompozitlerde görüldüğünü rapor etmişlerdir. Alkollü içeceklerin kompozitlerin aşınmaları üzerindeki etkisinin araştırıldığı bir başka çalışmada da, etanolün düşük $\mathrm{pH}^{\prime} ı$ sebebiyle kompozitlerin yüzeyinde erozyona neden olabileceği bildirilmiştir. ${ }^{41}$ Bagheri ve ark. ${ }^{6}$ ise $\% 10^{\prime}$ luk etanol ile suda bekletilen gruplar arasında renk değişimleri açısından belirgin bir fark bulamamış, bu durumun depolama süresinden veya etanol solüsyonunun konsantrasyonundan kaynaklanabileceğini bildirmişlerdir. Bir başka çalışmada \%75 etanol-su karışımında bekletilen örneklerde yumuşama meydana geldiği ve kompozitlerin doldurucu-matriks arayüzeyi boyunca ilerleyen yüzey ve yüzey altı çatlaklar sergilediği gösterilmiştir. ${ }^{16} \mathrm{Bu}$ çalışmada etanolde bekletilen örneklerde meydana gelen renk değişim değerlerinin, kabul edilebilir değer olan 1,8'in üzerinde olduğu tespit edilmiştir. Bu durumun etanolün kompozitlerin yüzey özelliklerinde meydana getirdiği değişikliklerden kaynaklanabileceği düşünülmektedir.

Voltarelli ve ark. ${ }^{42}$ gıda takliti solüsyonların kompozitlerin yüzey pürüzlülüğü üzerindeki etkilerini değerlendirdikleri çalışmalarında, heptanın kompozit grupları arasında istatistiksel olarak anlamlı bir etkiye neden olmadığını gözlemişlerdir. Domingos ve ark. ${ }^{43}$ yapay tükürüğün, kompozitlerin renk stabilitesini 30 günden sonra önemli ölçüde etkilediğini ve rezin matriks tarafından emilen yapay tükürük bileşenleri ile suyun, materyalin plastizasyonuna, yumuşamasına ve hidrolizine neden olarak renk değişimine karşı daha duyarlı hale getirebileceğini rapor etmişlerdir. Bizim çalışmamızda da, tükürükte bekletilmiş Beautifil Bulk Restorative örnekleri kahve solüsyonuna maruz bırakılması sonrası en az renk değişimine uğrayan grup olurken, aynı sonuç SonicFill grubu için heptana maruz kalan örneklerde tespit edilmiştir. Diğer kompozit materyallerin, farklı solüsyonlarda bekletilmesi renk değişimi açısından belirgin bir farka yol açmamıştır. Aynı zamanda çalışmadaki en düşük ve kabul edilebilir $\Delta$ E00 (s1.8) değerleri de heptanda bekletilmiş Filtek Bulk Fill Posterior Restorative ve SonicFill gruplarında gözlenmiştir.

\section{SONUÇ}

Bu çalışmanın sınırları içerisinde, test edilen tüm kompozitler kabul edilebilir renk değişim değerinin üzerinde $\triangle \mathrm{E} 00$ değerleri göstermiştir. Giomer yapıdaki bulk-fill kompozitin, gıdaları taklit eden solüsyonlara ve renklendirici solüsyona maruz kaldıklarında test edilen diğer kompozitlere oranla renk değişimine daha duyarlı olduğu, özellikle sitrik asitte bekletmenin bu grupta renklenmeyi arttırdığı sonucuna varılmıştır. Kompozit rezinlerde meydana gelen renk değişimlerinde materyalin fizikokimyasal özellikleri ve hastanın diyet alışkanlıkları yanında oral hijyen uygulamalarının da önemli bir belirleyici olması nedeniyle, ileriki çalışmalarda bu parametrenin de dahil edilmesinin, elde edilen sonuçlar açısından yararlı olacağı düşüncesindeyiz.

\section{KAYNAKLAR}

1. Badra VV, Faraoni JJ, Ramos RP, Palma-Dibb RG. Influence of different beverages on the microhardness and surface roughness of resin composites. Oper Dent 2005; 30: 213-219.

2. Asmussen E. Softening of BISGMA-based polymers by ethanol and by organic acids of plaque. Scand J Dent Res 1984; 92: 257-261.

3. Garcia FCP, Wang L, D'Alpino PHP, Souza JBd, Araújo PAd, Mondelli RFdL. Evaluation of the roughness and mass loss of the flowable composites after simulated toothbrushing abrasion. Braz Oral Res 2004; 18: 156-161.

4. Yap A, Lim L, Yang T, Ali A, Chung S. Influence of dietary solvents on strength of nanofill and ormocer composites. Oper Dent 2005; 30: 129-133.

5. Food and Drug Administration. FDA guidelines for chemistry and technology requirements of indirect food additive petitions. Washington, DC; 1976.

6. Bagheri R, Burrow MF, Tyas M. Influence of food-simulating solutions and surface finish on susceptibility to staining of aesthetic restorative materials. J Dent 2005; 33: 389-398.

7. Um CM, Ruyter IE. Staining of resin-based veneering materials with coffee and tea. Quin Int 1991; 22: 377-386.

8. Ashcroft AT, Cox TF, Joiner A. Evaluation of a new silica whitening toothpaste containing blue covarine on the colour of anterior restoration materials in vitro. J Dent 2008; 36: 26-31.

9. Tunc ES, Bayrak S, Guler AU, Tuloglu N. The effects of children's drinks on the color stability of various restorative materials. J Clin Pediatr Dent 2009; 34: 147-150.

10. Türkün LS, Türkün M. Effect of bleaching and repolishing procedures on coffee and tea stain removal from three anterior composite veneering materials. J Esthet Restor Dent 2004; 16: 290-301.

11. Güler AU, Kurt $S$, Kulunk T. Effect of various finishing procedures on the staining of provisional restorative materials. J Prosthet Dent 2005; 93: 453-458. 
12. Ertaş $E$, Güler AU, Yücel $A C$, Köprülü H, Güler E. Color stability of resin composites after immersion in different drinks. Dent Mater 2006; 25: 371-376.

13. Herrera LJ, Yebra A, Paravina RD. Color difference thresholds in dental ceramics. J Dent 2010; 38: 57-64.

14. Turssi CP, Hara AT, Serra MC, Rodrigues JR. Effect of storage media upon the surface micromorphology of resin-based restorative materials. J Oral Rehabil 2002; 29: 864-871.

15. Mortier E, Gerdolle DA, Jacquot B, Panighi MM. Importance of water sorption and solubility studies for couple bonding agent-resin based filling material. Oper Dent 2004; 29: 669-676.

16. Kao EC. Influence of food simulating solvents on resin composite and glass ionomer restorative cement. Dent Mater 1989; 5: 201-208.

17. Tanthanuch S, Kukiattrakoon B, Eiam-O-Pas K, Pokawattana K, Pamanee N, Thongkamkaew W, Kochatung A. Surface changes of various bulk-fill resin-based composites after exposure to different food-simulating liquid and beverages. J Esthet Restor Dent 2018; 30: 126-135.

18. Vouvoudi EC, Sideridou ID. Effect of food/oral-simulating liquids on dynamic mechanical thermal properties of dental nanohybrid light-cured resin composites. Dent Mater 2013; 29: 842-850.

19. Mohammadi E, Pishevar L, Mirzakouchaki Boroujeni P. Effect of food simulating liquids on the flexural strength of a methacrylate and silorane-based composite. PLoS One 2017; 12.

20. Chadwick RG, Mc Cabe JF, Walls AWG, Storer R. The effect of storage media upon the surface microhardness and abrasion resistance of three composites. Dent Mater 1990; 6: 123-128.

21. Örtengren U, Andersson F, Elgh U, Terselius B, Karlsson $\mathrm{S}$. Influence of $\mathrm{pH}$ and storage time on the sorption and solubility behaviour of three composite resin materials. J Dent 2001; 29: 35-41.

22. Silva SN, Reich AM, DeLeon Jr E, Schafer T, Rueggeberg FA, Fortson Jr WM. Staining potential differences between an infiltrative resin and an esthetic, flowable composite. J Esthet Restor Dent 2018; 30: 457-463.

23. Da Silva VA, Da Silva SA, Pecho OE, Bacchi A. Influence of composite type and light irradiance on color stability after immersion in different beverages. J Esthet Restor Dent 2018; 30: 390-396.

24. Ardu S, Duc O, Di Bella E, Krejci I, Daher R. Color stability of different composite resins after polishing. Odontology 2018; 106: 328-333.

25. Barutcigil C, Yildiz M. Intrinsic and extrinsic discoloration of dimethacrylate and silorane based composites. J Dent 2012; 40: 57-63.

26. Llena C, Fernandez S, Forner L. Color stability of nanohybrid resin based composites, ormocers and compo- mers. Clin Oral Invest. 2017; 21: 1071-1077.

27. Seghi RR, Johnston WM, O'Brien WJ. Performance assessment of colorimetric devices on dental porcelain. $J$ Dent Res. 1989; 68: 1755-1759.

28. Salas M, Lucena $C$, Herrera LJ, Yebra A, Della AB, Pérez MM. Translucency thresholds for dental materials. Dent Mater 2018; 34: 1168-1174.

29. Ghinea R, Pérez MM, Herrera LJ, Rivas MJ, Yebra A, Paravina RD. Color difference thresholds in dental ceramics. J Dent 2010; 38: 57-64.

30. Perez Mdel M, Ghinea R, Herrera LJ, Ionescu AM, Pomares H, Pulgar R. et al. Dental ceramics: a CIEDE2000 acceptability thresholds for lightness, chroma and hue differences. J Dent 2011; 39: 37-44.

31. International Standars Organization. Dentistry: guidance on color measurement. ISO/TR 28642. International Standards Organization, Geneva, Switzerland; 2011. 32. Paravina RD, Ghinea R, Herrera LJ, Bona AD, Igiel $C$, Linninger M. et al. Color difference thresholds in dentistry. J Esthet Restor Dent 2015; 27: 1-9.

33. Genç G, Toz T. Color stability of resin composites used for direct anterior restorations. OMÜ Diş Hek Fak Derg 2014; 15: 7-18.

34. Yu H, Wegehaupt FJ, Wiegand A, Roos M, Attin T, Buchalla W. Erosion and abrasion of tooth-colored restorative materials and human enamel. J Dent 2009; 37: 913-922.

35. Kooi T, Tan Q, Yap A, Guo W, Tay K, Soh M. Effects of food-simulating liquids on surface properties of giomer restoratives. Oper Dent 2012; 37: 665-671.

36. Wa C. Influence of oral fluid on composite resin and glass-ionomer cement. J Prosthet Dent 1984; 52: 182-189. 37. Yap A, Tan S, Wee S, Lee C, Lim E, Zeng K. Chemical degradation of composite restoratives. J Oral Rehabil 2001; 28: 1015-1021.

38. Deepa C, Krishnan VK. Effect of resin matrix ratio, storage medium, and time upon the physical properties of a radiopaque dental composite. J Biomater Appl. 2000; 14: 296-315.

39. Gürgan S, Önen A, Köprülü H. In vitro effects of alcohol-containing and alcohol-free mouthrinses on microhardness of some restorative materials. J Oral Rehabil 1997; 24: 244-246.

40. Gökay N, Türkün LŞ. Comparative analysis of abrasion and hardness properties of different composite resin materials. A Ü Diş Hek Fak Derg 2002; 28: 263-270.

41. Sarrett $D$, Coletti $D$, Peluso A. The effects of alcoholic beverages on composite wear. Dent Mater 2000; 16: 6267.

42. Voltarelli FR, Santos-Daroz CBd, Alves MC, Cavalcanti AN, Marchi GM. Effect of chemical degradation followed by toothbrushing on the surface roughness of restorative composites. J Appl Oral Sci 2010; 18: 585-590.

43. Domingos PA, Garcia PP, Oliveira AL, Palma-Dibb RG. 
Composite resin color stability: influence of light sources and immersion media. J Appl Oral Sci 2011; 19: 204-211. 